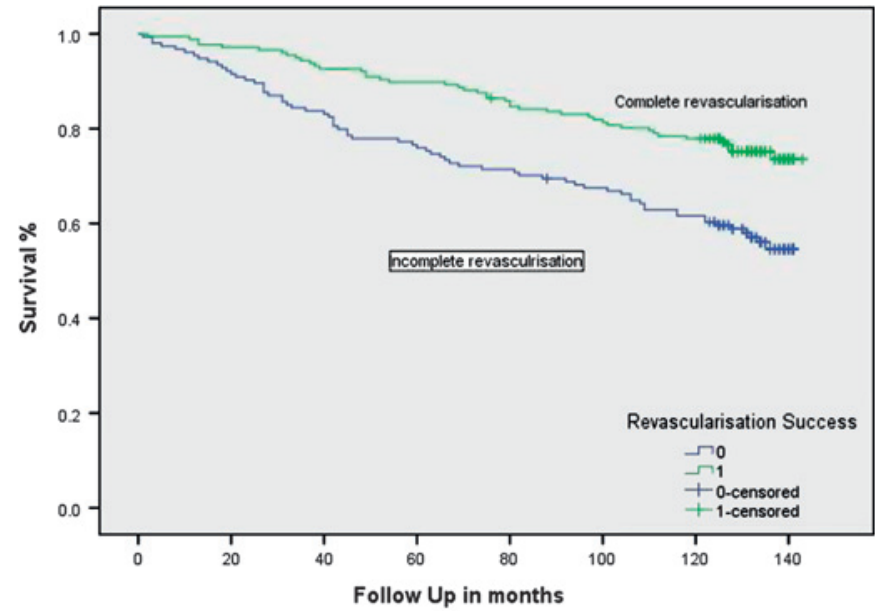

Revascularisation and Survival

Abstract 32 Figure 1

\begin{tabular}{l}
\hline 33 COMPLETENESS OF REVASCULARISATION PREDICTS \\
MORTALITY FOLLOWING PERCUTANEOUS CORONARY \\
INTERVENTION: UTILITY OF THE BCIS-1 JEOPARDY SCORE
\end{tabular}

doi:10.1136/heartjnl-2011-300198.33

K De Silva, G Morton, P Sicard, E Chong, A Indermeuhle, B Clapp, M Thomas, S Redwood, D Perera. St. Thomas' Hospital, King's College London, London, UK

Introduction Many coronary-scoring systems are complicated to use on a day-to-day basis, have varying degrees of reproducibility and exclude important subsets of patients such as those with previous coronary artery bypass grafts (CABG) or left main stem (LMS) disease (Abstract 33 table 1). The recently described BCIS-1 Myocardial Jeopardy score (BCIS-1 JS), a modification of the Duke Jeopardy score to include LMS and CABG, is simple to use and overcomes many of these limitations. We assessed the prognostic relevance of the BCIS-1 JS in patients undergoing percutaneous coronary intervention (PCI).

Abstract 33 Table 1

\begin{tabular}{llllll}
\hline & $\begin{array}{l}\text { Left Main } \\
\text { Stem Disease } \\
\text { classified }\end{array}$ & $\begin{array}{l}\text { Patients } \\
\text { with CABG } \\
\text { classified }\end{array}$ & $\begin{array}{l}\text { Ease } \\
\text { of use }\end{array}$ & $\begin{array}{l}\text { Relevance to } \\
\text { contemporary PCI }\end{array}$ & $\begin{array}{l}\text { Prognostic } \\
\text { validation }\end{array}$ \\
\hline $\begin{array}{l}\text { Duke Jeopardy } \\
\text { Score (Original) }\end{array}$ & $\mathrm{x}$ & $\mathrm{x}$ & $\sqrt{ }$ & $\mathrm{x}$ & $\sqrt{ }$ \\
Syntax Score & $\sqrt{ }$ & $\mathrm{x}$ & $\mathrm{x}$ & $\sqrt{ }$ & $\sqrt{ }$ \\
BCIS-1 JS & $\sqrt{ }$ & $\sqrt{ }$ & $\sqrt{ }$ & $\sqrt{ }$ & $\mathrm{x}$ \\
\hline
\end{tabular}

Methods Consecutive patients undergoing PCI between 2005 and 2009 a single cardiac centre were screened. Patients were eligible if they had undergone assessment of left ventricular function before PCI and the sample was enriched for coronary artery bypass graft (CABG) cases by using the following weighting-1 CABG: 3 nonCABG. Clinicians (who were blinded to clinical or outcome data) scored diagnostic and procedural coronary angiograms. The BCIS-1 JS was recorded before and after PCI (range: 0 to 12) and a Revascularisation Index (RI) calculated as $\mathrm{RI}=\left(\mathrm{JS} \mathrm{S}_{\mathrm{PRE}}-\mathrm{JS}_{\mathrm{POST}}\right) / \mathrm{J} \mathrm{S}_{\mathrm{PRE}}$. $\mathrm{RI}=1.0$ indicates full revascularisation and 0 indicates no revascularisation. The primary end-point was all-cause mortality. Mortality data was captured by tracking the database of the UK Office of National statistics. Predictors of outcome were assessed by univariate and multivariate analyses.

Results 660 patients were included (68 19 years). $44 \%$ presented as acute coronary syndromes with $41 \%$ having left ventricular dysfunction. Over a follow-up period of $2.6 \pm 1.1$ years there were 42 deaths. All-cause mortality was inversely related to baseline BCIS-1 JS (HR 2.20 (1.34 to 3.62), $\mathrm{p}=0.002$ ) and to post-PCI BCIS-1 JS (HR 3.98 (2.33 to 6.78), $\mathrm{p}=0.0001$ ). Increasing degrees of revascularisation were associated with improved survival (Abstract 33 figure 1); a revascularisation index of $\geq 0.67$ was associated with a survival advantage compared to a $\mathrm{RI} \leq 0.66$ (HR 0.39 ( 0.24 to 0.54 ), $\mathrm{p}=0.0001$ ) (Abstract 33 table 2). A multiple regression model, incorporating age, acuity of presentation, LV function and renal failure, demonstrated that $\mathrm{RI}=0.67-1$ continued to be an independent predictor of survival (HR $0.5195 \%$ CI 0.35 to 0.81, p=0.004) (Abstract 33 figure 1).

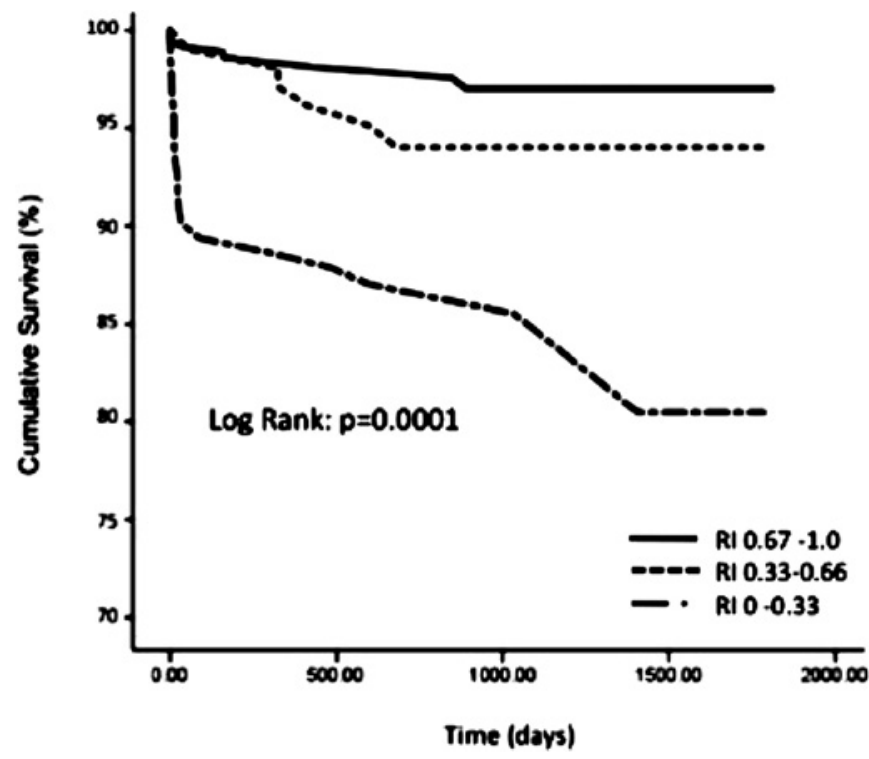

Abstract 33 Figure 1 Cumulative survival according to Revascularisation Index (RI).

Abstract 33 Table 2

\begin{tabular}{|c|c|c|c|c|}
\hline Variables & $\begin{array}{l}\text { Univariate analysis } \\
\text { HR ( } 95 \% \mathrm{CI})\end{array}$ & p value & $\begin{array}{l}\text { Multivariate } \\
\text { analysis HR }(95 \% \mathrm{CI})\end{array}$ & p value \\
\hline $\begin{array}{l}\text { Revascularisation } \\
\text { Index }(0.67-1)\end{array}$ & $0.36(0.24$ to 0.54$)$ & 0.0001 & $0.51(0.33$ to 0.81$)$ & 0.004 \\
\hline BCIS-1 JS pre PCI & $1.26(1.14$ to 1.39$)$ & 0.0001 & $1.14(0.65$ to 2.02$)$ & 0.65 \\
\hline BCIS-1 JS post PCI & $1.35(1.23$ to 1.48$)$ & 0.0001 & 1.78 (0.93 to 3.39$)$ & 0.08 \\
\hline LV impairment & $3.76(2.53$ to 5.58$)$ & 0.0001 & $1.97(1.21$ to 3.20$)$ & 0.007 \\
\hline Age & $1.04(1.01$ to 1.08$)$ & 0.01 & $1.04(1.00$ to 1.08$)$ & 0.05 \\
\hline Renal dysfunction & $5.82(2.77$ to 12.24$)$ & 0.0001 & $3.74(1.60$ to 7.37$)$ & 0.002 \\
\hline $\begin{array}{l}\text { Acute coronary } \\
\text { syndrome }\end{array}$ & $2.31(1.24$ to 4.30$)$ & 0.008 & $1.30(0.63$ to 2.66$)$ & 0.47 \\
\hline Cardiogenic shock & 14.56 (6.45 to 32.88 ) & 0.0001 & $2.83(0.69$ to 11.54$)$ & 0.15 \\
\hline Previous CABG & 3.35 (1.80 to 6.25$)$ & 0.0001 & $1.83(0.88$ to 3.82$)$ & 0.10 \\
\hline
\end{tabular}

Conclusion The BCIS-1 Jeopardy Score predicts mortality following PCI. Furthermore, it can be used to assess the degree of revascularisation, with more complete revascularisation (RI $\geq 0.67)$ conferring a survival advantage in the medium term.

\section{COMPARISON OF PCI VS CABG IN INSULIN TREATED AND NON-INSULIN TREATED DIABETIC PATIENTS IN THE CARDIA TRIAL}

doi:10.1136/heartjnl-2011-300198.34

${ }^{1} \mathrm{~A}$ Baumbach, ${ }^{2} \mathrm{~S}$ Kesavan, ${ }^{3} \mathrm{~K}$ Beatt, ${ }^{4} \mathrm{E}$ Cruddas, ${ }^{4} \mathrm{M}$ Flather, ${ }^{2} \mathrm{G}$ Angelini, ${ }^{5} \mathrm{R}$ Hall, ${ }^{6}$ A Kapur. ${ }^{1}$ Bristol Heart Institute, Bristol, UK; ${ }^{2}$ Bristol Heart Institute, Bristol, UK; 